\title{
Isolation and Identification of Non-Fermentative Gram Negative Bacilli
}

\author{
B. Ramchandra Reddy ${ }^{1}$, K. Shirisha ${ }^{2} *$, M. Singh and V. Kabra \\ ${ }^{1}$ Department of Microbiology, S.V.S. Medical College, Mahabubnagar, Telangana, India \\ ${ }^{2}$ Department of Microbiology, Malla Reddy Medical College for women, Hyderabad, \\ Telangana, India \\ *Corresponding author
}

\section{Keywords \\ Gram Negative Bacilli, Non- \\ Fermentative, Identification, Isolation}

Article Info

Accepted:

10 May 2019

Available Online:

10 June 2019

\section{A B S T R A C T}

Nonfermentative group of bacteria have been incriminated as emerging opportunistic pathogens, especially from hospital settings due to their increasing frequency of isolation from clinical specimens. Nonfermenters show natural resistance to a wide range of commonly used antibiotics. This study includes 50 isolates of nonfermenters from different clinical specimens like Pus, Sputum, blood and urine obtained from patients attending SVS Medical college \& Hospital from Jan 2007 to March 2008. Out of 50 nonfermenters, Pseudomonas sp. (82\%), Acinetobacter sp. (14\%), Alcaligens sp. (4\%) were isolated. Sensitivity pattern was Piperacillin (60\%), Amikacin (52\%), Ciprofloxacin (46\%), Ceftazidime (46\%), Cefotaxime (44\%), Cefi-pime (36\%), Gentamycin (24\%). This study showed that non-fermenters were frequently isolated from clinical specimens and that they are becoming resistant to the routinely used antibiotics and hence should be taken seriously rather than regarding them as contaminants or commensals.

\section{Introduction}

In medical microbiology, non fermentative group of bacteria have been incriminated as emerging opportunistic pathogens, especially from hospital settings. Current interest in non fermenters is fully justified by their increasing frequency of isolation from clinical specimens and their natural resistance to a wide range of commonly used antibiotics.

A number of these organisms are associated with serious disease in whom it is difficult to distinguish between clinical infection and colonization.
The nonfermenters comprise a heterogenous group of gram negative aerobic bacilli / coccobacilli, that are either incapable of utilizing carbohydrates as a source of energy or degrade them via oxidative rather than fermentative metabolic pathways.

The majority of non fermenters are found in nature as inhabitants of soil and water, as harmless parasites on mucous membranes of humans and animals, causing opportunistic infections in immunocompromized individuals. These organisms owe their invasiveness or infectivity to an altered immune status or an already debilitated host. 
The pathogenic potential of non fermenters has been proved beyond doubt by their frequent isolation from clinical samples and their association with the disease. Recent literature shows that these organisms cause generalized infections in man like urinary tract infections, septicemias, subacute bacterial endocarditis, and meningitis etc (Mackie and Mc Cartney, 1996).

About $15 \%$ of all the isolates encountered in clinical microbiological laboratories are non fermenters, out of which two thirds belong to Pseudomonas species (Bailey and Scott's, $10^{\text {th }}$ ed.).

Most laboratories include in their daily identification schemes, tests for the detection of Pseudomonas aeruginosa as it accounts for the majority of pathogenic nonfermenters.

Their identification requires more efforts as many members of this group are slow growing and requires the use of special culture media and biochemical tests (Koneman, 1988).

Since many of them are resistant to common antibiotics, early identification seems imperative to institute an appropriate treatment which may reduce the mortality due to these organisms in hospitalized patients.

Despite widespread use of antibiotics, the nosocomial infections still pose a great problem. Several factors influence the changing spectrum of etiological agents like increased level of drug resistance, bacterial synergism, some environmental risk factors and a higher number of compromised hosts.

For these reasons a lot of opportunists such as the non-fermenting gram negative bacilli emerge creating a significant therapeutic challenge.

\section{Materials and Methods}

Clinical Samples like pus', sputum, urine, blood and csf were collected from in and out patients attending S.V.S Hospital Mahabubnagar. During the period of 01.04.2007 to 30.01.2008.

The Specimens were inoculated on nutrient, blood and Mac conkey agar and incubated aerobically over night at $37^{\circ}$ for $24 \mathrm{hrs}$ and then examined next day.

Out of which 50 samples were showing growth of non - lactose fermenting colonies which were gram negative bacilli. They were then inoculated into TSI agar to see for acid production. An organism is considered non fermenter if it fails to produce any acid on TSI agar and is then subjected to a battery of tests as follows.

Gram stain for morphology

Hanging drop for motility

Study of cultural characters

BA $\} 37^{\circ}$

MA \} $37^{\circ}$

NA \} Both $37^{\circ} \mathrm{C}$ and $42^{\circ} \mathrm{C}$

For production of enzymes:

Catalase

Oxidase

Urease

Arginine dihydrolase

Nitrate reduction

For substrate utilization

Citrate test

For metabolism of proteins and aminoacids Gelatin liquefaction, Indole production

Utilization of carbohydrates of media containing 
Glucose Lactose Xylose Sucrose Maltose Mannitol

Antibiotic sensitivity testing by standard disc diffusion method

Results and Discussion

Non fermentive bacilli in clinical Specimens

Non - fermentative bacilli No. of isolates
Percentage

$\begin{array}{lll}\text { Pseudomonas spp. } & 41 & 82 \% \\ \text { Acinetobacter baumannii } & 5 & 10 \% \\ \text { Acinetobacter lwoffii } & 2 & 4 \% \\ \text { Alcaligens faecalis } & 2 & \\ 4 \% & & \end{array}$

- - - - - - - - - - - - - - - - - - - - - - -

Table above show the incidence of different non fermentative bacilli in 50 clinical specimens. 41 of the isolates were Pseudomonas spp forming the majority. 7 isolates were Acinetobacter spp; 4 isolates were Alkaligenes spp.

Sensitivity pattern of non - fermenters to some of the antibiotics

26 isolates found to be sensitive to $\mathrm{AK}$ (Amikacin), 23 isolates to CF (Ciprofloxacin),

23 isolates to CA (Ceftazidime), 22 isolates to $\mathrm{CE}$ (Cefotaxime), 18 isolates to $\mathrm{CPM}$ (Cefipime),

12 isolates $\mathrm{G}$ (Gentamicin), 7 isolates to $\mathrm{NF}$ (Norfloxacin).

Percentage of non fermenters sensitive and resistant to antibacterial agents

Table 4 shows the sensitivity pattern of nonfermentative bacilli to various antibiotics.
$69 \% P$. aeruginosa were sensitive to Amikacin

$58 \%$ to Ceftazidime, $69 \%$ Cefipime

$61 \%$ to Ciprofloxacin

Acinetobacter baumannii sensitive to Cefperazone.

P. fluorescens was sensitive to Ciprofloxacin

Acinetobacter lwoffi - sensitive to Amikacin $-100 \%$.

Alkaligenes faecalis - sensitive to Ciprofloxacin and Cefotaxime.

Percentage of nonfermenters resistant to antibacterial agents

$\begin{array}{lcc}\text { AMP } & - & 100 \\ \text { S } & - & 100 \\ \text { NF } & - & 86 \\ \text { NF } & - & 86 \\ \text { G } & - & 76 \\ \text { CPM } & - & 64 \\ \text { CE } & - & 56 \\ \text { CA } & - & 54 \\ \text { CF } & - & 54 \\ \text { AK } & - & 48\end{array}$

The isolation of non- fermenters frequently from clinical materials has proved their pathogenicity (Topley and Wilson's $8^{\text {th }}$ ed, 1999). One-fifth of all the gram negative bacilli isolated from various clinical specimens in a laboratory have been found to be non-fermenters (Bailey and Scott's, 10 ed).

About two-thirds of these are Pseudomonas spp. The remaining one-third include named and unnamed groups which are important because of their role in hospital acquired and frequent antimicrobial resistance (Homes et al., 1977) (Fig. 1-4 and Table 1-4). 
Table.1 Non fermentative bacilli in relation to the various clinical specimens i.e. pus, blood, urine; sputum, CSF and pleural fluid

\begin{tabular}{|l|l|l|l|l|l|l|}
\hline Isolate & Pus & Urine & Sputum & Blood & CSF & Pleural Fluid \\
\hline 1.P. aeruginosa & 10 & 7 & 4 & 3 & 1 & 1 \\
\hline 2.P. flourecens & 2 & 1 & 1 & - & - & - \\
\hline 3.P. cepacica & 1 & 1 & 1 & - & - & - \\
\hline 4.P. putida & 1 & 1 & 1 & - & - & - \\
\hline 5.P. stutzerl & 1 & 1 & - & 1 & - & - \\
\hline 6.P. maltophila & 1 & - & 1 & - & - & - \\
\hline 7.P. baumannii & 2 & 3 & - & - & - & - \\
\hline 8.A. lwoffii & - & 2 & - & - & - & - \\
\hline 9.Alk. faecalis & 1 & 1 & - & - & - & - \\
\hline Total & $\mathbf{1 9}$ & $\mathbf{1 7}$ & $\mathbf{8}$ & $\mathbf{4}$ & $\mathbf{1}$ & $\mathbf{1}$ \\
\hline
\end{tabular}

Table.2 Incidence of nonfermenters in relation to age

\begin{tabular}{|c|c|c|c|c|c|}
\hline CLINICAL SPECIMENS & NUMBER & 0-20YRS & 21-40YRS & 41-60YRS & >60YRS \\
\hline PUS & 19 & 2 & 4 & 4 & $\mathbf{9}$ \\
\hline URINE & 17 & - & 2 & 12 & $\mathbf{3}$ \\
\hline BLOOD & 4 & - & 3 & - & $\mathbf{1}$ \\
\hline SPUTUM & 8 & - & 3 & 4 & $\mathbf{1}$ \\
\hline PLEURAL FLUID \&CSF & $\mathbf{2}$ & - & $\mathbf{1}$ & - & $\mathbf{1}$ \\
\hline
\end{tabular}

Table.3 Sex wise distribution

\begin{tabular}{|c|c|c|c|c|}
\hline TOTAL & \multicolumn{2}{|c|}{ MALE } & \multicolumn{2}{c|}{ FEMALE } \\
\cline { 3 - 5 } NUMBER & NUMBER & PERCENTAGE & NUMBER & PERCENTAGE \\
\hline $\mathbf{5 0}$ & 35 & $70 \%$ & 15 & $30 \%$ \\
\hline
\end{tabular}


Table.4

\begin{tabular}{|c|c|c|c|c|c|c|c|c|c|c|c|c|c|c|c|c|c|c|}
\hline \multirow[t]{2}{*}{ Isolate } & \multicolumn{2}{|l|}{ AK } & \multicolumn{2}{|l|}{ CF } & \multicolumn{2}{|l|}{$\mathbf{C A}$} & \multicolumn{2}{|c|}{ CPM } & \multicolumn{2}{|l|}{ CE } & \multicolumn{2}{|l|}{ G } & \multicolumn{2}{|l|}{ NF } & \multicolumn{2}{|l|}{$\mathbf{A}$} & \multicolumn{2}{|l|}{$\mathbf{S}$} \\
\hline & $\mathrm{S}$ & $\mathrm{R}$ & $S$ & $\mathrm{R}$ & $S$ & $\mathrm{R}$ & $\mathrm{S}$ & $\mathrm{R}$ & $\mathrm{S}$ & $\mathrm{R}$ & $S$ & $\mathrm{R}$ & $\mathrm{S}$ & $\mathrm{R}$ & $S$ & $\mathrm{R}$ & $\mathrm{S}$ & $\mathbf{R}$ \\
\hline P. aeruginosa(26) & 69 & 31 & 61.5 & 38.5 & 58 & 42 & 69 & 31 & 50 & 50 & 38.5 & 61.5 & 11.5 & 88.5 & - & - & - & - \\
\hline P. flourecens(4) & 25 & 75 & 50 & 50 & 25 & 75 & - & 100 & 25 & 75 & - & 100 & - & 100 & - & 100 & - & 100 \\
\hline P. cepacia (3) & 33.3 & 66.7 & - & 100 & - & 100 & - & 100 & 33.3 & 66.7 & - & 100 & 33.3 & 66.7 & - & 100 & - & 100 \\
\hline P. putida (3) & 33.3 & 66.7 & - & 100 & - & 100 & - & 100 & 33.3 & 66.7 & - & 100 & 33.3 & 66.7 & - & 100 & - & 100 \\
\hline P. stutzeri (3) & 66.7 & 33.3 & - & 100 & 100 & - & - & 100 & 33.3 & 66.7 & - & 100 & - & 100 & - & 100 & - & 100 \\
\hline P. maltophilia (2) & 50 & 50 & - & 100 & 50 & 50 & - & 100 & 50 & 50 & - & 100 & - & 100 & - & 100 & - & 100 \\
\hline A. baumannii (5) & 20 & 80 & 40 & 60 & 20 & 80 & - & 100 & 60 & 40 & 20 & 80 & - & 100 & - & 100 & - & 100 \\
\hline A. lwoffii (2) & 100 & - & 50 & 50 & - & 100 & 50 & 50 & 50 & 50 & - & 100 & - & 100 & - & 100 & - & 100 \\
\hline Alk. faecalis & 50 & 50 & 100 & - & 50 & 50 & - & 100 & 100 & - & - & 100 & 100 & - & - & 100 & - & 100 \\
\hline
\end{tabular}

Fig.1

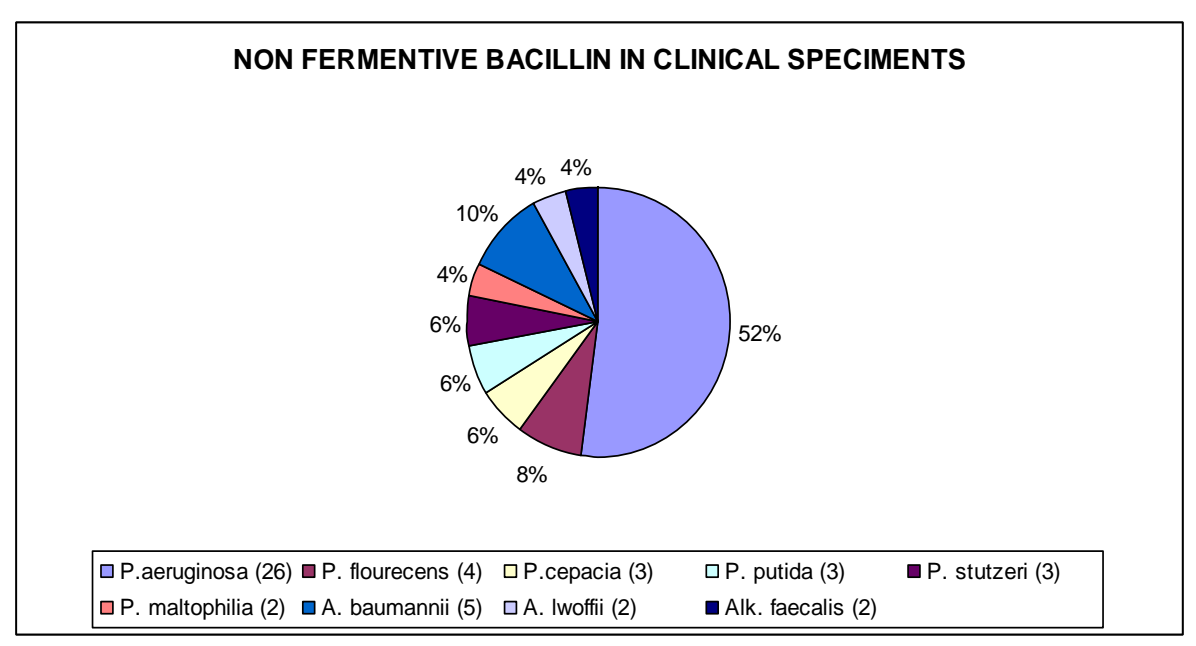


Fig.2 Incidence of nonfermenters in clinical specimens

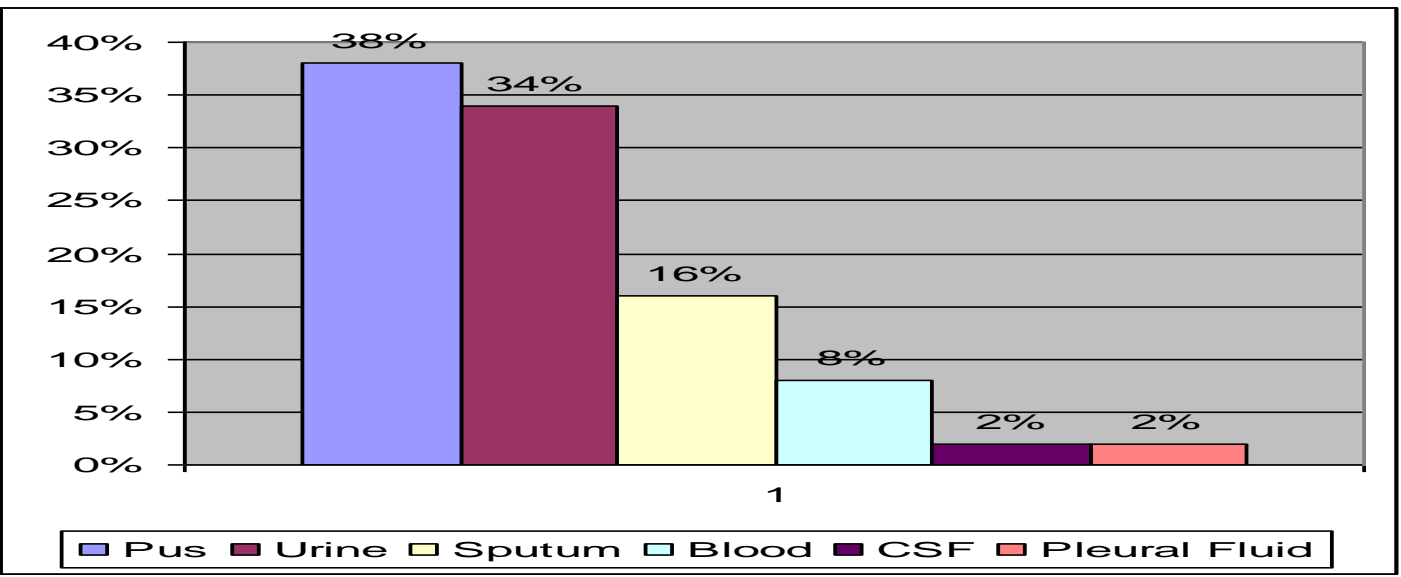

Fig.3

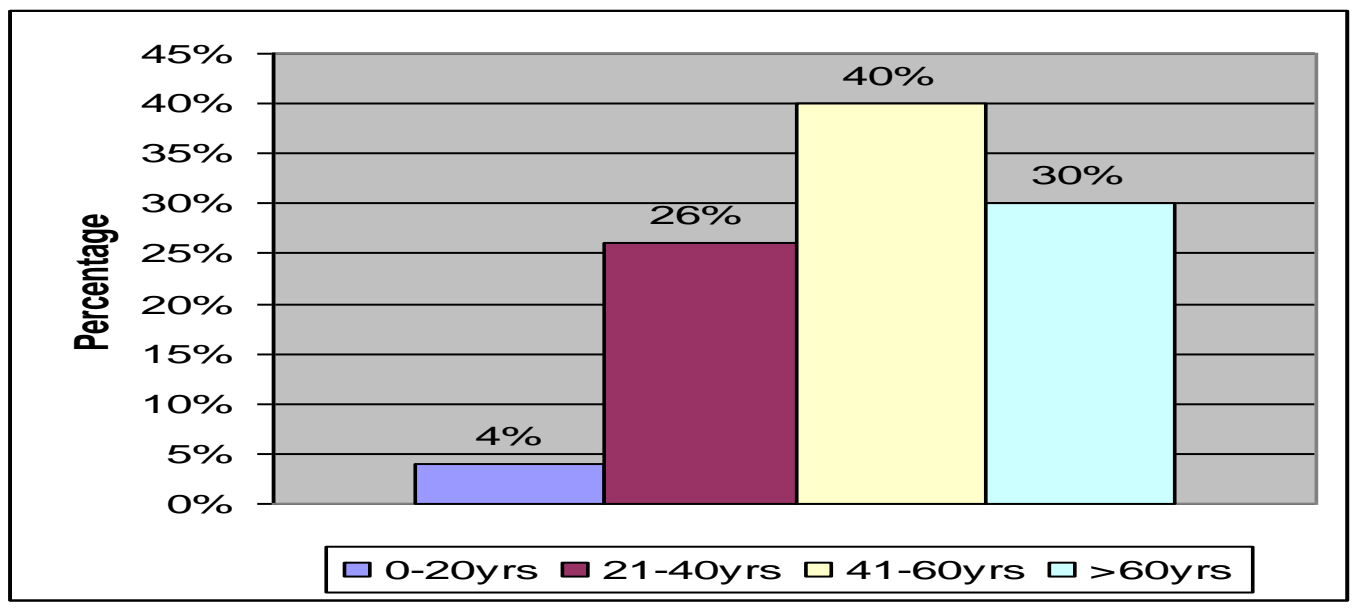

Fig.4

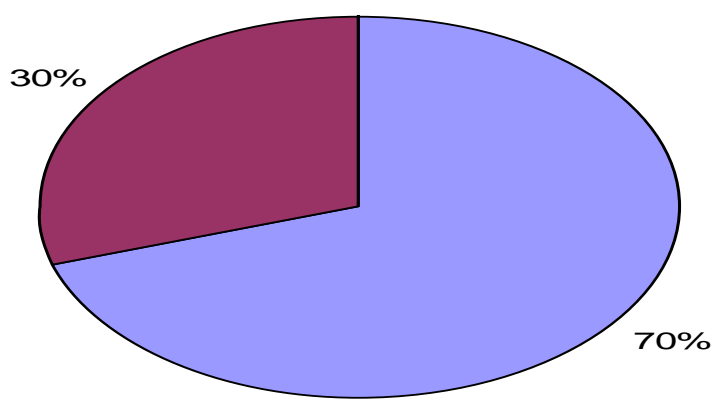

$\square$ Males $\square$ Females 
Pseudomonas species were found to be the predominant organisms isolated amongst the non - lactose fermenters in our study (82\%) which is in agreement with earlier studies (Picket et al., 1970; Gilardi et al., 1985).

The Pseudomonas species isolated were Ps aeruginosa (26) Ps. flourescens (4), Ps. cepacia (3), Ps. putida (3) Ps. stutzeri (3) Ps. maltophilia (2), other non - fermenters isolated were Acinetobacter baumannii (5), A. lowffii (2) and Alcaligensis faecalis (2)

Pseudomonas aeruginosa is resistant to a large number of commonly used drugs. They are usually susceptible to Aminoglycosides which are the drugs of choice.

Out of 26 clinical isolates of Pseudomonas aeruginosa (69\%) were sensitive to Amikacin and $58 \%$ to Ceftazidime these two being highly effective against Pseudomonas Antimicrobial susceptibility of all the isolates being resistant two or more drugs. Only $11.5 \%$ were sensitive to all drugs (Coyle et al., 1976; Venu et al., 1999).

Majority of the isolates were from males (70\%) which is akin with the studies of others (Coyle et al., 1976; Neena et al., 2001).

Most of the isolates were from patients between 41 and 60 (20) more then 60 years (15) and between 21 and 40 (13). This is in coincidence with earlier reports only two isolates were from patients between $0-20$ years.

Our studies showed that out of 50 - non fermenters, A. baumanni (3) and A. lwoffii (2) were isolated from urine. Only 2 Isolates of $A$. baumanni are from pus.

Alcaligenes faecalis (1) each from urine and pus have been isolated which is in agreement with other studies (Michell et al., 1966).
Non fermenters are normal inhabitants of the mucous membrane of humans and animals causing opportunistic infections. The pathogenic role of them has been proved beyond doubt by their frequent isolation from clinical samples and their association with this case. Since many of them are resistant to common antibiotics, early identification seems imperative.

As the organisms colonise in the tissues they should not be discarded as contaminants.

As non fermenters exhibit resistance to commonly used antibiotics combination of drugs may be useful in treating infections.

Conclusions are as follows:

1) Clinical Samples like Pus, Sputum, Urine, Blood and CSF were collected from in and out patients attending S.V.S Hospital Mahabubnagar. During the period of 01.04.2007 to 30.01.2008.

2) 50 isolates of non-fermenters characterized and identified.

3) Out of 50, 41 were Pseudomonas spp, 7 Acinetobacter $\mathrm{Sp}, 2$ Alkaligenes.

4) Majority of the isolates were from Pus (19), Urine (17), Sputum (8), Blood (4), Pleural fluid (1) and CSF (1).

5) Maximum number of isolates was from patients between the ages of 41 and60 years $(40 \%)$.

6) The non-fermentative bacilli were resistant to the commonly used antibiotics like Ampicillin and streptomycin

7) They were sensitive to Amikacin (52\%), Ciprofloxacin (46\%), Ceftazidine (46\%), Cefotaxime (44\%), Cefipime (36\%), Gentamicin (24\%), Norfloxacin (14\%)

8) Study shows that non-fermenters are frequently isolated from clinical specimens and that they are becoming resistant to the routinely used antibiotics and hence should be taken seriously rather 
than regarding them as contaminants or commensals.

\section{References}

Bailey and Scott`s Diagnostic Microbiology$10^{\text {th }}$ ed.

Coyle Gilchrist M M, Grewe P Roberts G: Flavobacterium meningitis in the hospital environment: J. Clin. Pathol; 1976. 29: 82-726.

Gilardi G L Pseudomonas; In Lennette E H; Balows A, Hansier W J Jr., Truant J P; Editors; Manual of clinical Microbiology; $4^{\text {th }}$ edn. Washington D C: 1985: Am. Society for Microbiology.

Homes B. Owen R J, Evan A, Maluick H, Wilcor W R; Ps. Paucimobilis, a new species isolated from human clinical specimens in the hospital environment and other source; Int. J. Syst. Bacteriol; 1977; 27: 133 - 46.

Koneman E W., Alen S D, Dowell V R (Jr), Willaiam M J, Sommers H M, Winn W C (Jr): The non-fermentative Gram negative bacilli, In: Colour atlas and text book of diagnostic microbiology; J B Lipincott Co, Philladelphia, 1988; $3^{\text {rd }}$ edn. 157

Mackie and Mc Cartney. Practical medical microbiology. $14^{\text {th }}$ ed.1996.

Michell, R.G.. Hayward A C: Post operative urinary tract infections caused by contaminated irrigating fluid: Lancer 1966. 1: 793-795

Neena, V Kharangate maria. J.W. Pinto Rod rignes S. Mangala P. Venkar Characterisation of Non - Fermenters from clinical samples: Vol. 49, 2001, 324-326

Picket M J, Marso E, Manclark C R: Non fermentative bacilli associated with man: III. Pathogenecity and antibiotic susceptibility, Am. J. Clin. Pathol: 1970:54:178

Pickett M J. Pedersen M M: Non fermentative bacilli associated with man: II. Detection and identification. Am. J. Clin.Pathol:1970:54:164.

Topley and Wilson's Principles of bacteriology, virology and immunity, $8^{\text {th }}$ ed. 1999.

Venu, Rama, Sikka and D.R. Arora, Isolation and susceptibility patterl of Non Fermenting gram negative bacilli from clinical samples. 1999. Volume 17,1, 14-17.

\section{How to cite this article:}

Ramchandra Reddy, B.K. Shirisha, M. Singh and Kabra, V. 2019. Isolation and Identification of Non-Fermentative Gram Negative Bacilli. Int.J.Curr.Microbiol.App.Sci. 8(06): 1003-1010. doi: https://doi.org/10.20546/ijcmas.2019.806.122 